\title{
Cognitive Deficits Feature of Male with Attention Deficit Hyperactivity Disorder-Based on the Study of WISC-IV
}

\author{
Wenqing Jiang, Yan Li, Yasong Du* and Juan Fan \\ Department of Child and Adolescent Psychiatry, Shanghai Mental Health Center, School of Medicine, Shanghai Jiaotong University, Shanghai, China
}

\begin{abstract}
Objective: This study aims to explore the characteristics of children with attention deficit hyperactivity disorder (ADHD) in the Fourth Edition of Wechsler Intelligence (WISC-IV).

Methods: The boys with ADHD were tested by WISC-IV, and the comparisons with healthy children were performed.

Results: The total IQ, $(\mathrm{t}=-4.964, P<0.001)$, general ability index $(\mathrm{t}=-2.443, P=0.016)$ and cognitive efficiency index $(\mathrm{t}=-5.810, P<0.001)$ of the study group were significantly lower than that of the control group, of which, the working memory $(\mathrm{t}=-5.354, P<0.001)$, processing speed $(\mathrm{t}=-4.593, P<0.001)$ and its various sub-tests scores of the subscales for cognitive processing efficiency index were significantly lower than that of the control group. The incidence of the "relatively low cognitive efficiency" feature of the study group $(69.23 \%)$ was significantly higher than that of the control group $(46.15 \%)\left(x^{2}=6.923, P=0.009\right)$. The performance of the learning factor in the study group was correlated with the total IQ and working memory of WISC.
\end{abstract}

Conclusions: Children with ADHD have intellectual characteristics of relatively low cognitive efficiency.

Keywords: WISC-IV; ADHD; Cognitive efficiency; Working memory; Processing speed

\section{Introduction}

Attention deficit hyperactivity disorder (ADHD) is the most common behavioral problems in children and adolescents. The current study suggests that the incidence of ADHD was 5.29\%, and that of the male was higher than that of the female [1].

The current study believes that children with ADHD have defects in cognitive function, which leads to children's academic and other social dysfunction [2]. The intelligence can reflect the overall response of individual cognitive ability [3] to a large extent. Therefore, how is the performance of children with ADHD in the intelligence measurement, how were the attention defect characteristics affect children's performance in the measurement? What is the particularity of cognitive characteristics for children with ADHD reflected in the intelligence measurement? What are the differences among the scores of IQ test and its different subtypes of children with ADHD?

The intelligence of ADHD children is often considered to be in or slightly below the average, which may contain a number of reasons, such as low birth weight that may affect the individual's fluid intelligence, while the lower fluid intelligence is very relevant with the individual attention [4]. However, some researchers have suggested that an inability to concentrate may affect poor test performance of children in measurement, thus affecting their mental measurement results. In some studies, it is found that the performance of attention deficits is lowly related to the IQ levels. The affect of attention problems on the results of IQ is $2-5$ points [5].

In addition, ADHD children have a certain characteristic performance in intelligence measurement. In Mayes and Calhoun [6] study, it is found that the performance of children with ADHD is "inefficient cognitive characteristics" in the measurement of WISC-IV. In the Spanish versions of WISC-IV, the studies suggest that ADHD children have even worse performance in the working memory and processing speed compared with that of the healthy control group.
These above studies prompt that the WISC-IV evaluates the cognitive deficits of ADHD children to some extent [7].

Thaler's study found that the reduction of the processing speed was related with increased scores of attention deficit symptom, and the low processing speed can predict ADHD diagnosis of attention deficit predominant type [8]. The processing speed and working memory damage were related with behavioral dysfunction. So it was thought that the scores outline of WISC-IV subscales helped predicting ADHD type, symptoms and other factors. In Yang's study, it was found that processing speed was weak aspect of Taiwan ADHD children and adolescents [9], especially for ADHD children with attention deficit as the main types, the performance of processing speed was especially poor, which was similar to Thaler's findings.

Wechsler [10] intelligence scale for children, the forth edition (WISC-IV) (Chinese Edition) has been revised and was currently gradually used. However, few studies reported on the performance characteristics of children with ADHD in the WISC-IV. We hypothesized that children with ADHD had specific performance in WISC-IV, this performance feature was associated with cognitive deficits, but different with intelligence measurement results of different subtypes for ADHD. In this study, a case-control designed study was conducted. ADHD boys were taken as objects, the intelligence and structure of children with ADHD were studied through case-control

*Corresponding author: Yasong Du, Department of Child \& Adolescent Psychiatry, Shanghai Mental Health Center, School of Medicine, Shanghai Jiaotong University, No. 600 Wanping Road, Shanghai 200030, China, Tel: +86 021 64387250-3420; Fax: +86 021 64387986; E-mail: yswqcn@126.com

Received January 16, 2015; Accepted February 12, 2015; Published February 21,2015

Citation: Jiang W, Li Y, Du Y, Fan J (2015) Cognitive Deficits Feature of Male with Attention Deficit Hyperactivity Disorder-Based on the Study of WISC-IV. J Psychiatry 18: 252 doi: 10.4172/2378-5756.1000252

Copyright: @ 2015 Jiang W, et al. This is an open-access article distributed under the terms of the Creative Commons Attribution License, which permits unrestricted use, distribution, and reproduction in any medium, provided the original author and source are credited 
approach in order to investigate the cognitive defects feature in IQ test of the ADHD children.

\section{Materials and Methods}

\section{Subjects}

Research Group: the 6-14 year-old boys admitted in January, 2012 to December, 2013 to outpatient department of Mental Health Center in Medicine College of Shanghai Jiaotong University School with IQ $\geq$ 85 (WISC-IV), right-handed, in line with diagnostic criteria of DSMIV on children with attention deficit hyperactivity disorder (ADHD), without taking any central stimulant drugs or other psychoactive drugs before the experiment were selected. The research group was further divided into three groups according to the classification criteria in DSM-IV.

Exclusion criteria: organic disease and other serious psychiatric disorders, including organic mental disorders, schizophrenia, personality disorders and other mental disorders; neurodegenerative disorders, traumatic brain injury or cerebral vascular disease; serious heart, liver, kidney dysfunction and other major physical illness history or a history of drug dependence were excluded.

Control group: male students in the first grade in the primary school to sophomore in junior high school from Zhabei and Hongkou District, Shanghai with IQ $\geq 85$ (WISC-IV) and right-handed were included. The children with a diagnosis of ADHD were excluded. The remaining exclusion standards were the same with that of the study group.

This study was conducted in accordance with the declaration of Helsinki. This study was conducted with approval from the Ethics Committee of Shanghai Jiaotong University School of Medicine. Written informed consent was obtained from all participants' guardians.

\section{Research tools}

Common demographic data were surveyed, including: gender, age, education and so on.

Wechsler Intelligence Scale for Children-IV (WISC-IV) Wechsle [10] can be decomposed into two most parts: "general ability index" and "cognitive efficiency index". The "total intelligence quotient", "general ability index" and "cognitive efficiency index" share the same cut-off point, mean score of which is 100 and with 15 standard deviation. A difference of more than 10 between the two was considered to be significantly different, suggesting the existence of "relatively low cognitive efficiency" feature. "General ability index" included two subscales: "verbal understanding" and "perceptual reasoning". "cognitive efficiency index" included two subscales: "working memory" and "processing speed". "Verbal understanding" included three subscales: "similar", "word" and "understanding". "Perceptual Reasoning" included three subscales: "building blocks" and "concept drawing". "Matrix Reasoning". "Working memory" included two subscales: "back number" and "alphanumeric character". "Processing speed" included two subscales: "decode" and "symbol Search". No supplementary subscales were used in this study.

Conners parent symptom questionnaire (Fan Juan) [11]: the questionnaire was prepared by the American scholar Conners in 1969 for evaluating the severity of ADHD symptoms in children. The domestic studies suggested that the questionnaire had good reliability and validity, which can be used in assessment of Chinese ADHD children. PSQ totally had 48 entries, six factors including conduct problems, learning problems, psychosomatic disorders, impulsivityhyperactivity, anxiety and hyperactivity index were obtained using $0-3$ four degree score method. The higher score prompted more serious corresponding questions.

Kiddie-Sade-Present and Lifetime Version (K-SADS-PL) was a semi-structured diagnostic tool [12]. The current and previous psychotic episodes of children and adolescents were assessed on the basis of DSM-III -R and DSM-IV, including: non-formulary guide checks, $\alpha$ screening, $\beta$ supplementary examination completion list, $\chi$ diagnostic supplement, $\delta$ lifetime diagnosis of summary list, $\varepsilon$ Global Assessment Scale (GAS) was used to assess the overall functioning level in children. The study omitted the last part.

\section{Survey Method}

The research group included the outpatient boys diagnosed by the psychiatrists on the basis of DSM-IV on diagnostic criteria for children with ADHD. The children in the study group were performed K-SADSPL after signing the informed consent by the parents to exclude heavy psychotic disorder. Subsequently, the children met the inclusion criteria were treated with WISC-IV tests. The questionnaire was performed to the parents.

The children in the control group were from elementary schools in Zhabei and Hongkou District. 2-3 male students were selected from each grade of the junior high school in the first grade to second grade in accordance with the random number, after the clinical interview, the children were performed K-SADS-PL to exclude heavy psychotic disorders. Then children and adolescents meet the entry criteria were performed neuropsychological measurement and psychological questionnaires for the parents. The children with "hyperactivity index" score higher than 20 in the Conners' questionnaire filled by the parents were excluded. A total of effective data of 52 students were finally completed, collected and statistically analyzed.

\section{Statistical Analysis}

All data were processed using SPSS11.5 to establish a database and statistical analysis. The statistical method comprised $t$ test of the mean value in the two groups. Chi-square test was performed to the enumeration data.

\section{Results}

\section{General demographic data}

78 cases with age ranged from 6 to 14 years old (mean age of $10.03 \pm$ 2.53 years old) were selected into the study group, including 46 children had attention deficits, 9 cases had hyperactivity type, and 23 children had the mixed diseases. The control group included 52 cases with age ranged from 6 to 14 years old (mean age of $10.77 \pm 2.62$ years old). The mean age of the study group had no significant difference compared with that of the control group.

The various subtypes and PSQ scores in the study group were significantly higher than that of the control group. Comparisons among the study group showed that the "hyperactive - impulsive" factor scores of attention deficit-based main type were significantly lower than that of hyperactivity predominant or hybrid type. "Learning factor" score of hyperactivity predominant type were significantly lower than attention defect or predominant or hybrid type (Table 1).

\section{Intelligence comparison}

The WISC-IV results of children in the two groups showed that 
Citation: Jiang W, Li Y, Du Y, Fan J (2015) Cognitive Deficits Feature of Male with Attention Deficit Hyperactivity Disorder-Based on the Study of WISC-IV. J Psychiatry 18: 252 doi: 10.4172/2378-5756.1000252

Page 3 of 6

the total intelligence, general capability index, "verbal understanding" subscale, "similar" sub-test research group, cognitive processing efficiency index and various subscales of test scores of the study group were significantly lower than that of the control group. Subtype scores of the study group in the intelligence test had significant differences compared with that of the control group. Comparison among the study group showed that the hybrid "Matrix Reasoning" score was significantly lower than that of the attention deficit and impulsivity and hyperactivity predominant type (Table 2 ).

\section{Internal structure of children's IQ}

In the study group, 38 cases had "the cognitive efficiency index" equaled to or less than 90 (48.72\%). 36 cases scored 91-110 (46.15\%). Four cases scored 110 points or more (5.13\%). While in the control group, 7 cases had "the cognitive efficiency index" equaled to or less than 90 (13.46\%). 27 cases scored 91-110 (51.92\%). 18 cases scored 110 points or more (34.62\%). The score distribution of the two groups had significant differences $\left(\chi^{2}=27.448, P<0.001\right)$.

In the study group, the occurrence rate of "cognitive efficiency index" was significantly lower than that of the "general ability index" (relatively low cognitive efficiency) (69.23\%). In the control group, the occurrence rate of the "cognitive efficiency index" was significantly lower than that of the "general ability index" (46.15\%). The characteristic incidence rate of the "relatively low cognitive efficiency" in the study and control groups had significant differences $\left(\chi^{2}=6.923, P=0.009\right)$.

In the study group, the feature occurrence rate of "relatively lower cognitive efficiency index" for attention deficiency predominant type was 71.74 , while that of the mixed type was $60.87 \%$. The occurrence rate of the two groups had no significant differences $\left(\chi^{2}=0.834, P=0.361\right)$.

\section{Intelligence measurement and correlated symptoms}

The correlation analysis between the intelligence test results of the study group and Conners' Parent Symptom Questionnaire was performed. Of which, PSQ learning factor and total IQ, working memory subscale scores had correlation. The anxiety factor and perceived reasoning subscale scores were correlated (Table 3).

\section{Discussion}

In China, the common used intelligence measurement tool was the second edition of the Wechsler intelligence test revised by Mr. Gong, in which the main set of scales was divided into the intellectual verbal and nonverbal parts with inadequate pertinence for assessing individual's cognitive ability. The fourth edition of Wechsler intelligence test was the new intelligence measurement tool built up on the basis

\begin{tabular}{|c|c|c|c|c|c|c|}
\hline & \multicolumn{4}{|c|}{ Study group } & \multirow{2}{*}{$\begin{array}{c}\text { Control group } \\
(n=52)\end{array}$} & \multirow[b]{2}{*}{$\mathrm{t} / P$} \\
\hline & Total $(n=78)$ & $\begin{array}{c}\text { Attention defect } \\
\text { predominant type }(n=46)\end{array}$ & $\begin{array}{c}\text { Hyperactivity predominant } \\
\text { type }(n=9)\end{array}$ & Mixed type $(n=23)$ & & \\
\hline Age & $10.03 \pm 2.53$ & $10.61 \pm 2.78$ & $9.11 \pm 0.93^{* *}$ & $9.22 \pm 2.11^{*}$ & $10.77 \pm 2.62$ & $1.618 / 0.108$ \\
\hline Behavior factor & $26.69 \pm 5.78$ & $25.52 \pm 5.49^{* *}$ & $28.78 \pm 6.32^{* *}$ & $28.27 \pm 5.81^{* *}$ & $15.56 \pm 2.61$ & $14.805 / 0.000$ \\
\hline Learning factor & $12.82 \pm 2.28$ & $13.17 \pm 2.09^{* *}$ & $10.89 \pm 2.03^{* *}$ & $12.86 \pm 2.44^{* *}$ & $6.77 \pm 2.40$ & $14.493 / 0.000$ \\
\hline Psychosoma factor & $6.88 \pm 1.98$ & $6.76 \pm 2.14^{* *}$ & $7.89 \pm 2.09^{* *}$ & $6.73 \pm 1.49^{*}$ & $5.75 \pm 1.45$ & $3.745 / 0.000$ \\
\hline Hyperactivity factor & $11.44 \pm 2.35$ & $10.65 \pm 2.27^{* *}$ & $12.78 \pm 1.48^{* *}$ & $12.55 \pm 2.18^{* *}$ & $5.42 \pm 1.32$ & $18.540 / 0.000$ \\
\hline Anxiety factor & $6.58 \pm 1.95$ & $6.22 \pm 1.63^{* *}$ & $7.11 \pm 2.76$ & $7.14 \pm 2.10^{* *}$ & $5.35 \pm 1.33$ & $4.293 / 0.000$ \\
\hline Hyperactivity index & $26.71 \pm 4.28$ & $25.87 \pm 4.42^{* *}$ & $27.78 \pm 3.80^{\star *}$ & $28.05 \pm 3.89^{* *}$ & $13.73 \pm 2.29$ & $22.301 / 0.000$ \\
\hline
\end{tabular}

* , score comparisons between subtype of ADHD in the study group and the control group had significant difference $(p<0.05)$;

${ }^{* *}$, score comparisons between subtype of ADHD in the study group and the control group had very significant difference $(p<0.01)$.

Table 1: Clinical manifestation comparisons of the study group and the control group.

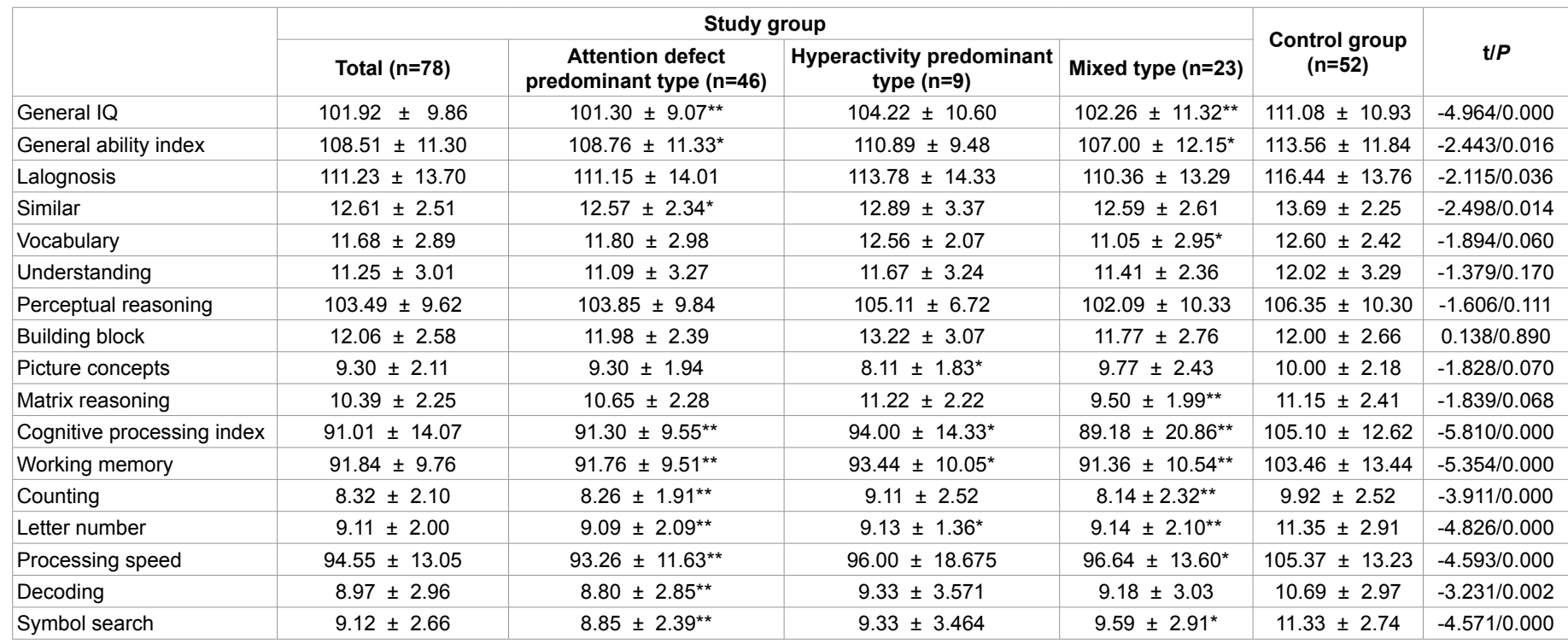

*, score comparisons between subtype of ADHD in the study group and the control group had significant difference $(p<0.05)$;

${ }^{* *}$, score comparisons between subtype of ADHD in the study group and the control group had very significant difference $(p<0.01)$.

Table 2: Comparisons of IQ characteristics between the study group and the control group. 


\begin{tabular}{|c|c|c|c|c|c|c|c|c|c|c|c|}
\hline & General IQ & Lalognosis & $\begin{array}{l}\text { Perceptual } \\
\text { reasoning }\end{array}$ & $\begin{array}{l}\text { Working } \\
\text { memory }\end{array}$ & $\begin{array}{c}\text { Processing } \\
\text { speed }\end{array}$ & $\begin{array}{c}\text { Behavior } \\
\text { factor }\end{array}$ & $\begin{array}{c}\text { Learning } \\
\text { factor }\end{array}$ & $\begin{array}{l}\text { Psychosoma } \\
\text { factor }\end{array}$ & $\begin{array}{l}\text { Hyperactivity } \\
\text { factor }\end{array}$ & Anxiety factor & $\begin{array}{l}\text { Hyperactivity } \\
\text { index }\end{array}$ \\
\hline General IQ & 1 & & & & & & & & & & \\
\hline Lalognosis & $\begin{array}{l}0.705 / \\
0.000\end{array}$ & 1 & & & & & & & & & \\
\hline $\begin{array}{l}\text { Perceptual } \\
\text { reasoning }\end{array}$ & $\begin{array}{l}0.699 / \\
0.000\end{array}$ & $\begin{array}{l}0.284 / \\
0.012\end{array}$ & 1 & & & & & & & & \\
\hline $\begin{array}{l}\text { Working } \\
\text { memory }\end{array}$ & $\begin{array}{l}0.497 / \\
0.000\end{array}$ & $\begin{array}{l}0.143 / \\
0.214\end{array}$ & $\begin{array}{l}0.221 / \\
0.053\end{array}$ & 1 & & & & & & & \\
\hline $\begin{array}{l}\text { Processing } \\
\text { speed }\end{array}$ & $\begin{array}{l}0.576 / \\
0.000\end{array}$ & $\begin{array}{l}0.090 / \\
0.436\end{array}$ & $\begin{array}{l}0.272 / \\
0.017\end{array}$ & $\begin{array}{l}0.165 / \\
0.152\end{array}$ & 1 & & & & & & \\
\hline $\begin{array}{l}\text { Behavior } \\
\text { factor }\end{array}$ & $\begin{array}{l}-0.131 / \\
0.256\end{array}$ & $\begin{array}{l}-0.124 / \\
0.286\end{array}$ & $\begin{array}{l}-0.132 / \\
0.257\end{array}$ & $\begin{array}{l}-0.051 / \\
0.659\end{array}$ & $\begin{array}{l}0.015 / \\
0.897\end{array}$ & 1 & & & & & \\
\hline $\begin{array}{l}\text { Learning } \\
\text { factor }\end{array}$ & $\begin{array}{c}-0.368 / \\
0.001\end{array}$ & $\begin{array}{c}-0.177 / \\
0.126\end{array}$ & $\begin{array}{c}-0.223 / \\
0.053\end{array}$ & $\begin{array}{c}-0.262 / \\
0.022\end{array}$ & $\begin{array}{c}-0.216 / \\
0.061\end{array}$ & $\begin{array}{l}0.314 / \\
0.005\end{array}$ & 1 & & & & \\
\hline $\begin{array}{l}\text { Psychosoma } \\
\text { factor }\end{array}$ & $\begin{array}{l}-0.069 / \\
0.550\end{array}$ & $\begin{array}{l}-0.077 / \\
0.510\end{array}$ & $\begin{array}{l}0.039 / \\
0.739\end{array}$ & $\begin{array}{l}-0.099 / \\
0.394\end{array}$ & $\begin{array}{l}-0.091 / \\
0.435\end{array}$ & $\begin{array}{l}0.215 / \\
0.060\end{array}$ & $\begin{array}{l}0.150 / \\
0.193\end{array}$ & 1 & & & \\
\hline $\begin{array}{l}\text { Hyperactivity } \\
\text { factor }\end{array}$ & $\begin{array}{l}0.012 / \\
0.914\end{array}$ & $\begin{array}{l}0.106 / \\
0.360\end{array}$ & $\begin{array}{c}-0.085 / \\
0.463\end{array}$ & $\begin{array}{c}-0.029 / \\
0.805\end{array}$ & $\begin{array}{l}0.123 / \\
0.290\end{array}$ & $\begin{array}{l}0.364 / \\
0.001\end{array}$ & $\begin{array}{l}0.143 / \\
0.215\end{array}$ & $\begin{array}{c}-0.006 / \\
0.961\end{array}$ & 1 & & \\
\hline $\begin{array}{l}\text { Anxiety } \\
\text { factor }\end{array}$ & $\begin{array}{l}-0.198 / \\
0.084\end{array}$ & $\begin{array}{l}-0.050 / \\
0.668\end{array}$ & $\begin{array}{l}-0.355 / \\
0.002\end{array}$ & $\begin{array}{l}-0.225 / \\
0.051\end{array}$ & $\begin{array}{l}-0.024 / \\
0.838\end{array}$ & $\begin{array}{l}0.265 / \\
0.020\end{array}$ & $\begin{array}{l}0.128 / \\
0.267\end{array}$ & $\begin{array}{l}0.175 / \\
0.128\end{array}$ & $\begin{array}{l}0.172 / \\
0.134\end{array}$ & 1 & \\
\hline $\begin{array}{l}\text { Hyperactivity } \\
\text { index }\end{array}$ & $\begin{array}{l}-0.132 / \\
0.253\end{array}$ & $\begin{array}{l}-0.123 / \\
0.292\end{array}$ & $\begin{array}{l}-0.041 / \\
0.727\end{array}$ & $\begin{array}{l}-0.086 / \\
0.459\end{array}$ & $\begin{array}{l}0.037 / \\
0.748\end{array}$ & $\begin{array}{l}0.670 / \\
0.000\end{array}$ & $\begin{array}{l}0.561 / \\
0.000\end{array}$ & $\begin{array}{l}0.176 / \\
0.125\end{array}$ & $\begin{array}{l}0.708 / \\
0.000\end{array}$ & $\begin{array}{l}0.210 / \\
0.067\end{array}$ & 1 \\
\hline
\end{tabular}

Table 3: Correlation of intellectual performance and clinical characteristics in the study group.

of cognitive psychology, the mainland of China has completed the amendments to the sets of scales [10]. In this study, this tool was used to explore the cognitive characteristics of ADHD boys. ADHD children were considered to be relative lack of cognitive abilities. This study assumed that the ADHD children's performance was worse in WISCIV measurement, and this lack had correlation with their cognitive abilities. All ADHD children with different subtypes showed the lack of cognitive ability, the cognitive performance among different subtypes may be different.

According to the study results, in comparison with the development of healthy children. The multiple overall performance of "general intelligence", "general cognitive index" or "cognitive efficiency index" of ADHD children was worse than that of the health boys. In the WISC-IV, the total IQ can better represent the overall cognitive level of the individual. The "general ability index" was more closer to the "intelligence" thought in past, representing the general ability of the individual to deal with the problem. "Cognitive efficiency index" represented the speed and effectiveness of the self-processing information. The results of this study prompted that ADHD children had the overall inefficient cognitive ability, they not only had poor ability to grasp cognitive experience and deal with general issues, but also had inadequate ability to deal with everyday cognitive information. The Chinese researchers used WISC-IV to perform measurements for children with ADHD, the results showed that the performance of ADHD children in four subscales was poorer than that of the healthy children. This was consistent with the results of this study.

So, if there was a possibility that similar to or slightly lower IQ levels of ADHD children than that of healthy children was due to the attention defect characteristics affecting the ADHD children's performance in the measurement of intelligence. For example, Jepsen et al. [5] study believed that the total IQ level of ADHD children decreased by $2-5$ points due to attention deficits. Through correlation analysis between symptom performance and individual intelligence test results, the study found that the learning ability of the children with ADHD was related with the overall IQ scores and working memory subscale scores. The anxiety factor was correlate with the perceived reasoning subscale score, while the scores of the behavior factor and hyperactivity factor on behalf of individuals hyperactivity, attention defects and other core symptoms of ADHD had no significant association with the performance of individual intelligence, suggesting that attention deficit, hyperactivity and other features had no correlation with the intellectual performance in the measurement. However, some studies have found comorbid externalizing behavior, the severity of externalizing problems was associated with the presence of intelligence [13], which had discrepancies with the results found in the study, the possible reason was that the extreme ADHD cases with obvious lack of intelligence were excluded. In addition, Thaler et al. [8] study believed that low processing speed was related with the clinical manifestations of unability to focus attention, while processing speed and working memory defects were associated with the detriment of behavioral function. The study found that the correlation of intelligence and learning problems, and no similar findings were found.

In this study, after excluding the poor overall IQ (Total IQ<85), the incidence of the situation that the overall IQ level of cognitive efficiency for ADHD children was still below the average (IQ<90) was nearly a half, the incidence of such lower cognitive efficiency significantly was significantly higher than that of the development of healthy children. The children with "cognitive processing efficiency index" score lower than "general ability index" by 10 or above were described as "relatively low cognitive efficiency" features, then it was found that nearly $2 / 3$ of the internal intelligent structure for ADHD boys had relatively low cognitive efficiency characteristics, while the proportion of this feature for children with healthy development was only about $1 / 2$. Cognitive efficiency index reflected capacity and speed of processing information for the individual reactions. It can be considered according to the results of this study: compared with the healthy children, the access, memory, storage and ability to process information of the children with ADHD in their daily lives were more insufficient, this inefficiency exacerbated overall cognitive ability defects of children with ADHD. This findings echoed the results of several studies $[6,7,9]$. The inefficiency of cognitive efficiency for ADHD children deserved attention. Children indeed had difficulty to receive information, inefficiency, slow and other clinical features in their daily life, school learning and other environments [14]. These difficulties constituted lack of basic cognitive abilities in $\mathrm{ADHD}$ children, suggesting that cognitive interventions for ADHD 
children needed to understand their cognitive efficiency features, such as increased information input intensity frequency and others.

In addition, a review in literature found that the working memory damage feature of children with ADHD was already a widely accepted concept [15]. For example, Gau and Chiang [16] study found that the early attention deficit symptoms was correlated with the late verbal and visual spatial short-term memory. The attention deficit in childhood can predict short-term memory impairment in adolescence. This study again confirmed the presence of damage to working memory in children with ADHD. Working memory was an important constitution of the individual executive function, which has gained widespread acceptance in children with ADHD, even some researchers believed that the executive function defects may be the core defects of ADHD children. In addition, processing speed did not get more attention, but it involved visual retrieval, short-term visual memory, handeye coordination, fine motor and other multiple neuropsychological abilities in the measurement of the WISC-IV. Previous studies have demonstrated the presence of hand-eye coordination, visual search, write ability inefficiency in ADHD children $[17,18]$. These fundamental inefficiencies of awareness ability defects constituted the ADHD children's cognitive deficits. In Shanahan et al. [19] study, the role of processing speed in ADHD children was focused to discuss, the results suggested that the processing speed defects was the shared neuropsychological defects of ADHD and dyslexia, affirming the processing speed defects in children with ADHD, which was consistent with the results of this study. However, it also indicated that this basic capability inefficiency may be related to high comorbidity of ADHD children [20].

In comparisons of intelligence measurement for different subtypes of children with ADHD, the hybrid matrix reasoning score was significantly lower than that of the other two subtypes, other IQ latitude score had no significant differences between the groups. In addition, according to the results of this study, the incidence of cognitive efficiency for ADHD children with attention deficit predominant type was relatively low than that of the hybrid ADHD children, but this difference was not significant. In Pasini et al. [21] study, it was also thought that no difference between the cognitive abilities of different subtypes for ADHD in children. Skogli et al. [22] study also considered that the performance of executive function did not differ between different subtypes of ADHD. The results of the two studies were similar. However, Mayes compared the performance of ADHD subtypes and the comorbidity in Gordon and WISC-IV diagnostic systems, and found that the damage on the processing speed of the attention deficit-predominant ADHD children was more obvious than that of the hybrid [23]. Yang et al. [9] also found that the low "processing speed" shortcomings of the attention deficit-predominant children were more apparent. Some other cognitive measures also believed that the performance of mixed ADHD in several cognitive tasks was more obvious than that of attention-deficient predominant type [24]. In this study, ADHD boys had large age span, the sample size was relative lack, the "cognitive" feature differences among different subtypes of children remained to be further studied in order to clear.

\section{Defects and Deficiencies}

The Chinese researchers have used WISC-IV measurements to perform measurement on children with ADHD. According to the study results, the children with ADHD had intelligent defects, the performance of ADHD children in four subscales was poorer compared with that of the healthy children, the internal structure of intelligence for children with ADHD was not investigated in the study. The study set the total IQ of the enrolled children was more than 85 points. Although the similar results were obtained, the study could not take "ADHD children's mental health of children was lower than that of the healthy children as the conclusion. Compared with the overall performance of intelligence, more attention was paid on the internal features of mental retardation for ADHD children's cognitive efficiency in this study.

\section{Conflict of Interest}

All authors have no conflict of interest regarding this paper.

\section{Acknowledgement}

This study was supported by 2012 National Natural Science Foundation of China "Executive function defect hypothesis of disruptive behavior disorders pathogenesis and brain imaging studies" (Task Number: 81271510). Shanghai Municipal Health Bureau Youth Project in 2012 "Adolescent emotion regulation of disruptive behavior barriers and brain imaging studies" (Task Number: 20124y042). Hospital-level issues Shanghai mental Health Center in 2011 "Preliminary study of intervention project for Child disruptive behavior disorder angles" (Mission statement No.: 2011-YJ-07). Specialists project of Shanghai Mental Health Center Medical (Project No.: 2013-YJTSZK-04).

\section{References}

1. Polanczyk G, de Lima MS, Horta BL, Biederman J, Rohde LA (2007) The Worldwide Prevalence of ADHD: A Systematic Review and Metaregression Analysis. Am J Psychiatry 164: 942-948.

2. Bunford N, Brandt NE, Golden C, Dykstra JB, Suhr JA, et al. (2014) Attention Deficit Hyperactivity Disorder Symptoms Mediate the Association between Deficits in Executive Functioning and Social Impairment in Children. J Abnorm Child Psychol.

3. Klasik A, Janas-Kozik M, Krupka-Matuszczyk I, Augustyniak E (2006) Cognitive functions, their development and modern diagnostic methods. Przegl Lek 63 29-34.

4. Lahat A, Van Lieshout RJ, Saigal S, Boyle MH, Schmidt LA (2014) ADHD among young adults born at extremely low birth weight: the role of fluid intelligence in childhood. Front Psychol 5: 446

5. Jepsen JR, Fagerlund B, Mortensen EL (2009) Do attention deficits influence IQ assessment in children and adolescents with ADHD? J Atten Disord 12 551-562.

6. Mayes SD, Calhoun SL (2006) WISC-IV and WISC-III profiles in children with ADHD. J Atten Disord 9: 486-493.

7. San Miguel Montes LE, Allen DN, Puente AE, Neblina C (2010) Validity of the WISC-IV Spanish for a clinically referred sample of Hispanic children. Psychol Assess 22: 465-469.

8. Thaler NS, Bello DT, Etcoff LM (2013) WISC-IV Profiles Are Associated With Differences in Symptomatology and Outcome in Children With ADHD. J Atten Disord 17: 291-301.

9. Yang P, Cheng CP, Chang CL, Liu TL, Hsu HY, et al. (2013) Wechsler Intelligence Scale for Children 4th edition-Chinese version index scores in Taiwanese children with attention-deficit/hyperactivity disorder. Psychiatry Clin Neurosci 67: 83-91.

10. Wechsle D (2003) WISC-IV Administration and scoring Manual. San Antonio, TX: The Psychological Corporation.

11. Fan J, Du YS, Wang LW (2006) The norm and reliability of the Conners Parent Symptom Questionnaire in Chinese urban children. Shanghai Archives of Psychiatry 17: 321-323.

12. Kaufman J, Birmaher B, Brent D, Rao U, Flynn C, et al. (1997) Schedule for affective disorders and schizophrenia for School-Age Children-Present and Lifetime Version (K-SADS-PL): initial reliability and validity data. J Am Acad Child Adolesc Psychiatry 36: 980-988.

13. Di Trani M, Casini MP, Capuzzo F, Gentile S, Bianco G, et al. (2011) Executive and intellectual functions in attention-deficit/ hyperactivity disorder with and without comorbidity. Brain Dev 33: 462-469.

14. Karalunas SL, Huang-Pollock CL, Nigg JT (2012) Decomposing attention- 
Citation: Jiang W, Li Y, Du Y, Fan J (2015) Cognitive Deficits Feature of Male with Attention Deficit Hyperactivity Disorder-Based on the Study of WISC-IV. J Psychiatry 18: 252 doi: 10.4172/2378-5756.1000252

deficit hyperactivity disorder (ADHD)-related effects in response speed and variability. Neuropsychology 26: 684-694.

15. Fassbender C, Schweitzer JB, Cortes CR, Tagamets MA, Windsor TA, et al. (2011) Working Memory in Attention Deficit/Hyperactivity Disorder is Characterized by a Lack of Specialization of Brain Function. PLoS One 6: e27240.

16. Gau SS, Chiang HL (2012) Association between early attention-deficit/ hyperactivity symptoms and current verbal and visuo-spatial short-term memory. Res Dev Disabil 34: 710-720.

17. Shen IH, Lee TY, Chen CL (2012) Handwriting performance and underlying factors in children with Attention Deficit Hyperactivity Disorder. Res Dev Disabil 33: 1301-1309.

18. Kim S, Chen S, Tannock R (2014) Visual function and color vision in adults with Attention-Deficit/Hyperactivity Disorder. J Optom 7: 22-36.

19. Shanahan MA, Pennington BF, Yerys BE, Scott A, Boada R, et al. (2006) Processing Speed Deficits in Attention Deficit/Hyperactivity Disorder and Reading Disability. J Abnorm Child Psychol 34: 585-602.
20. Jensen CM, Steinhausen HC (2014) Comorbid mental disorders in children and adolescents with attention-deficit/hyperactivity disorder in a large nationwide study. Atten Defic Hyperact Disord. Epub ahead of print.

21. Pasini A, Paloscia C, Alessandrelli R, Porfirio MC, Curatolo P (2007) Attention and executive functions profile in drug naive ADHD subtypes. Brain Dev 29 400-408.

22. Skogli EW, Egeland J, Andersen PN, Hovik KT, Øie M (2014) Few differences in hot and cold executive functions in children and adolescents with combined and inattentive subtypes of ADHD. Child Neuropsychol 20: 162-181.

23. Mayes SD, Calhoun SL, Chase GA, Mink DM, Stagg RE (2009) ADHD subtypes and co-occurring anxiety, depression, and oppositional-defiant disorder: differences in Gordon diagnostic system and Wechsler working memory and processing speed index scores. J Atten Disord 12: 540-550.

24. Nikolas MA, Nigg JT (2013) Neuropsychological performance and attention-deficit hyperactivity disorder subtypes and symptom dimensions. Neuropsychology 27: 107-120. 